\title{
Agronomic effects of a reciprocal translocation in a widely grown Spanish barley variety
}

\author{
A. Farré • A. Visioni - I. Lacasa-Benito • \\ L. Cistué $\cdot$ J. Jansen $\cdot$ I. Romagosa
}

Received: 7 September 2011 / Accepted: 2 February 2012/Published online: 16 February 2012

(C) The Author(s) 2012. This article is published with open access at Springerlink.com

\begin{abstract}
A large spontaneous reciprocal translocation is present in a widely grown Spanish barley cv. 'Albacete'. It has been hypothesized that high popularity of 'Albacete' with farmers, particularly in semi-arid areas where barley is grown under rainfed conditions, may be due to the presence of this translocation. Agronomic effects of this translocation were studied at two locations and two growing seasons in a set of 245
\end{abstract}

A. Farré · A. Visioni - I. Lacasa-Benito · I. Romagosa Department of Plant Production and Forest Science, University of Lleida, Lleida, Spain

e-mail: alba.farre@pvcf.udl.cat

A. Visioni

e-mail: andrea.visioni@pvcf.udl.cat

I. Lacasa-Benito

e-mail: isa.lac.ben@gmail.com

A. Farré · J. Jansen

Department of Biometrics, Wageningen University and Research Centre, Wageningen, The Netherlands e-mail: johannes.jansen@wur.nl

L. Cistué

Estación Experimental de Aula Dei, CSIC,

Zaragoza, Spain

e-mail: lcistue@eead.csic.es

I. Romagosa ( $\square)$

Centre UdL-IRTA, University of Lleida, Lleida, Spain

e-mail: iromagosa@pvcf.udl.es doubled haploid lines derived from the $F_{1} s$ of four crosses involving 'Albacete'. The results have shown a significant positive main effect of the translocation on the thousand kernel weight and a significant environment by translocation interaction for the thousand kernel weight, lodging and tiller number. However, the results do not support the hypothesis that this chromosomal structural change alone provides an increased adaptation to low-yielding sites.

Keywords Reciprocal translocation - Barley · Breeding · Adaptation

\section{Introduction}

Spontaneous reciprocal translocations seldomly occur in cultivated barley; only a few cases have been described (Konishi and Linde-Laursen 1988). Translocations usually reduce the agronomic value; 'Albacete' is the only extensively cultivated barley variety carrying a reciprocal translocation without apparent loss of agronomic value. In Spain it has been grown for decades on up to 1 million ha/year. The reciprocal translocation was identified in a meiotic analysis of semi-sterile $\mathrm{F}_{1}$ hybrids involving 'Albacete' [Luis Cistué, personal communication; see also Farré et al. (2011)]. Farré et al. (2012) performed a molecular and cytogenetic characterization of the reciprocal translocation and determined the position of 
the translocation breakpoints. Drought is the main factor limiting the yield of cereals in environments with high temperatures and limited rain during the grain-filling period (López-Castañeda and Richards 1994). It is unknown whether the reciprocal translocation has a positive effect on drought tolerance and other traits that make it worth to be introduced in the barley germplasm. In the present study, 248 doubled haploid (DH) lines from four crosses involving 'Albacete' as one of the parents will be used to phenotypically characterize the effects of the presence of the reciprocal translocation.

\section{Materials and methods}

Plant material

Different agronomic traits were evaluated in $245 \mathrm{DH}$ lines of barley derived from the $\mathrm{F}_{1} \mathrm{~s}$ between 'Albacete' and 'Barberousse', 'Plaisant' and 'Orria' and a DH line derived from 'Plaisant' $\times$ 'Orria'. 'Albacete' is a variety with a long cycle and an alternative growth habit. It is drought tolerant with a stable grain yield production. 'Barberousse' is known for its good produc tivity and easy adaptation; it is sensitive to drought. 'Plaisant' shows good adaptation and high-yield under Spanish conditions. 'Orria' is a Spanish variety of CIMMYT origin, well adapted to fertile, rainfed environments. The DH lines were scored for the presence of the reciprocal translocation using molecular data (Farré et al. 2011). The number of lines carrying/not carrying the translocation were $41 / 54$, $18 / 20,40 / 27,36 / 9$ for $\mathrm{A} \times \mathrm{B}, \mathrm{A} \times \mathrm{O}, \mathrm{A} \times \mathrm{P}$ and $\mathrm{A} \times(\mathrm{P} \times \mathrm{O})$, respectively.

\section{Phenotyping}

Four field trials were carried out at two rainfed locations in North-Eastern Spain in 2008/2009 and 2009/2010: Gimenells $\left(41^{\circ} 37^{\prime} \mathrm{N}, 0^{\circ} 22^{\prime} \mathrm{E}, 248 \mathrm{~m}\right)$ and Foradada $\left(41^{\circ} 51^{\prime} \mathrm{N}, 1^{\circ} 0^{\prime} \mathrm{E}, 407 \mathrm{~m}\right)$. Experiments con- tained one or two replicates per DH line augmented by four replicated checks in a rectangular set-up. The traits measured were: days to heading, days to jointing, days to maturity, number of spikes in $50 \mathrm{~cm}$, yield, thousand kernel weight (TKW), early vigour, till number, total height and lodging.

Data analysis

For each population the average broad sense heritability was estimated. For each trait, best linear unbiased estimates (BLUEs) of DH individuals were estimated by removing spatial effects. The BLUEs were further analysed using the mixed model facilities of Genstat version 13 (Payne et al. 2009), heterogeneous variances within population were corrected.

\section{Results and discussion}

Broad sense heritabilities $\left(\mathrm{H}^{2}\right)$ ranged from 0.27 to 0.84 (Table 1). A highly significant main effect of the reciprocal translocation was obtained for TKW; DH lines carrying the reciprocal translocation had a greater TKW than those with a standard chromosome arrangement (34.8 vs 32.9 gr, respectively). No significant main effects were found for the other traits. For TKW, lodging and till number a significant environment by translocation interaction was found. More lodging was recorded at Gimenells and for the RT genotypes. Differences in the response of the RT to till number may be associated to specific meteorological conditions. In conclusion, the results do not support the hypothesis that the reciprocal translocation alone provides an increased adaptation to low-yielding sites; TKW is the only trait which is clearly enhanced by the reciprocal translocation. Future work combining the results from this study with QTL analysis will be carried out to characterize the effects of the reciprocal translocation and QTL simultaneously. 


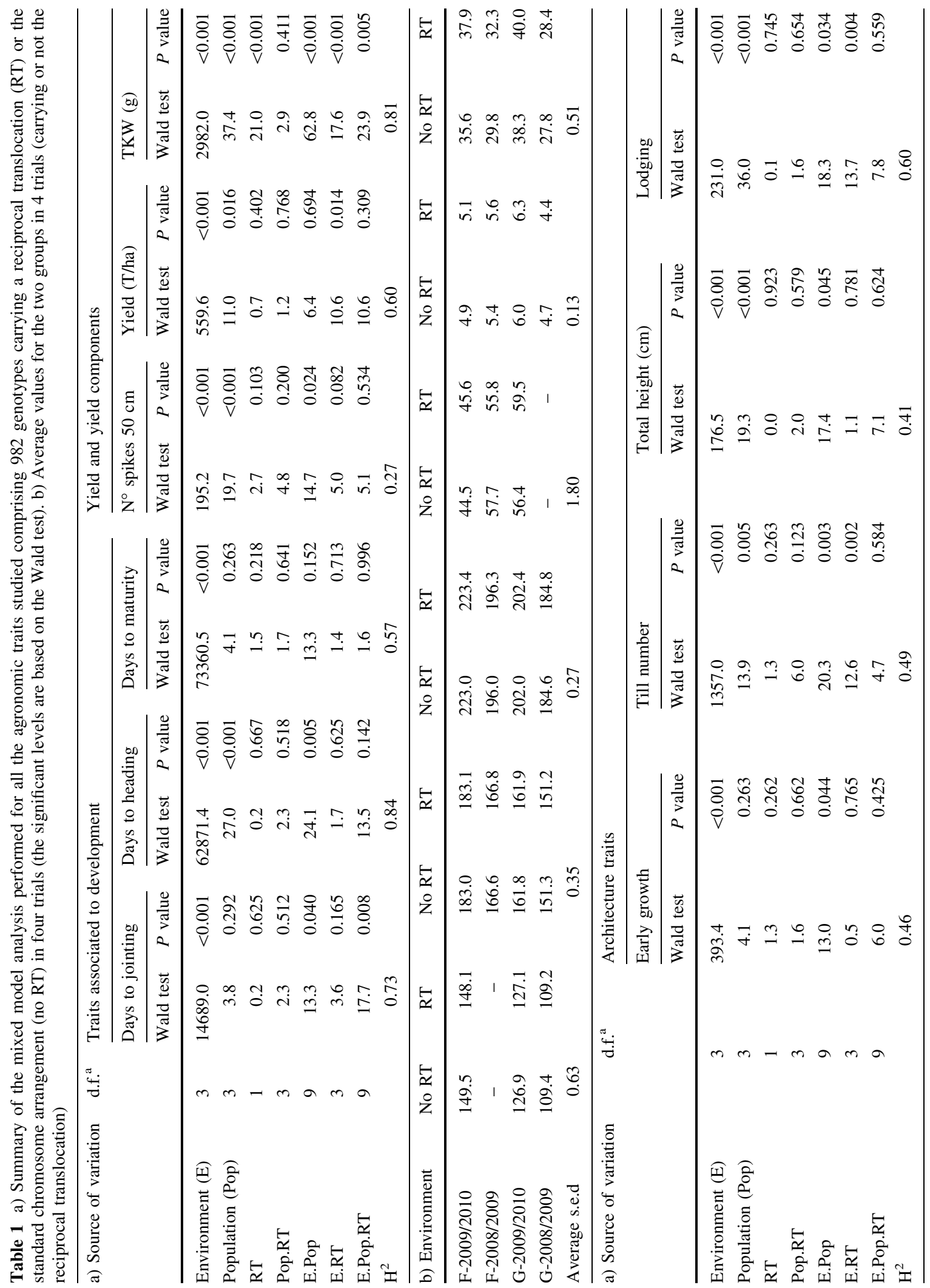




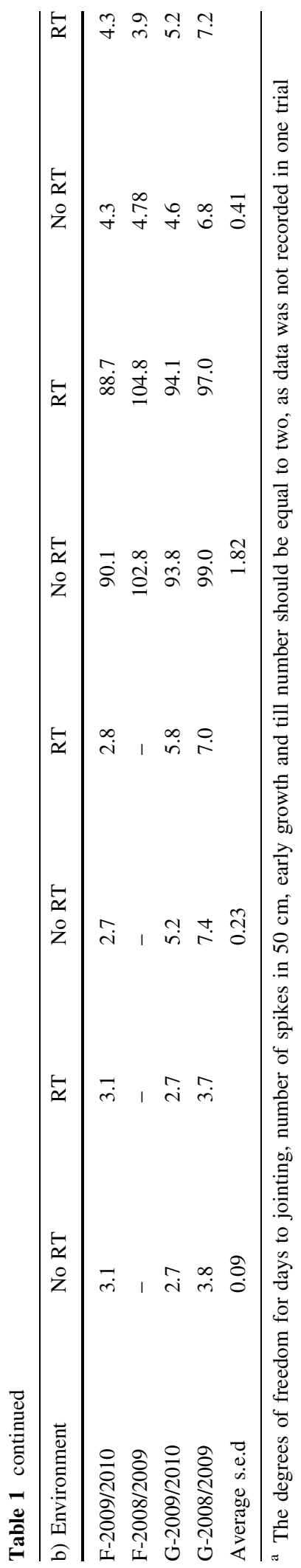

Acknowledgments This study has been supported by the Spanish Ministry of Science and Innovation (Project AGL200805541-C02 and the Agrogenomics CONSOLIDER Center).

Open Access This article is distributed under the terms of the Creative Commons Attribution License which permits any use, distribution, and reproduction in any medium, provided the original author(s) and the source are credited.

\section{References}

Farré A, Lacasa-Benito I, Cistué L, de Jong JH, Romagosa I, Jansen J (2011) Linkage map construction involving a reciprocal translocation. Theor Appl Genet 122:10291037

Farré A, Cuadrado A, Lacasa-Benito I, Cistué L, Schubert I, Comadran J, Jansen J, Romagosa I (2012) Genetic characterization of a reciprocal translocation present in a widely grown barley variety. Mol Breeding doi:10.1007/ s11032-011-9698-z

Konishi T, Linde-Laursen I (1988) Spontaneous chromosomal rearrangements in cultivated and wild barleys. Theor Appl Genet 75:237-243

López-Castañeda C, Richards RA (1994) Variation in temperate cereals in rainfed environments. I. Grain yield, biomass and agronomic characteristics. Field Crops Res 37:51-62

Payne RW, Murray DA, Harding SA, Baird DB, Soutar DM (2009) GenStat for Windows. Introduction, 13th edn. VSN International, Hemel Hempstead 